\title{
THE EFFECT OF UPFC PROPER PLACEMENT ON THE LIMIT OF THE STATIC LOADING IN THE POWER SYSTEM
}

\author{
M. A. Kamarposhti*, P. Nouri \\ Young Researchers and Elite Club, Jouybar Branch, Islamic Azad University, Jouybar, Iran
}

\begin{abstract}
Proper placement of reactive power sources, which are parallel capacitors or flexible alternating current transmission systems controllers (FACTS), can effectively improve loading level and the system voltage stability margin. The aim of this study is to investigate the effect of UPFC (Unified Power Flow controller) on power system static loading. To this end, continuation power flow is used to calculate the maximum loading point and its corresponding megawatts margin. Using PSAT software, the proper place of this controller on the -IEEE 14-bus power system, is determined. The results show that UPFC effectively increases the static loading margin of power system.
\end{abstract}

Key words: loading, voltage stability margin, Megawatts, UPFC.

\section{INTRODUCTION}

The only way to avoid voltage collapse in a power system is to reduce consumed reactive power or to increase reactive power before reaching to collapse point of voltage. Employing flexible alternating current transmission systems could be the best option to improve and control voltage instead of creating new transmission lines. Employing reactive power sources, which are parallel capacitors or flexible alternating current transmission systems controllers (FACTS), in proper place, can effectively improve loading level and thus the system voltage stability[1].

There are no considerable research studies in the past about showing the exact location of FACTS devices. The authors in [2] provide modal analysis using the eigenvalues of the reduced Jacobian matrix to locate weak buses of the system which are similar to singular values and singular vectors for identifying proximity of the voltage collapse. But, as shown in [3], due to their nonlinear behavior, they are not suitable indices for predicting Bifurcation point of

\footnotetext{
*Correspondence to: Mehrdad Ahmadi, Young Researchers and Elite Club, Jouybar Branch, Islamic Azad University, Jouybar, Iran, Email: m.ahmadi@jouybariau.ac.ir
}

voltage collapse, close to collapse point. In [4] the author presets an interesting index as Index of closeness to voltage collapse to choice weak buses, and uses annealing simulation technique (flux) to locate the reactive sources, which is very difficult and inefficient method. In [5] a voltage stability index has been introduced for finding the critical buses, but this index does not provide enough information about stability margin of the system. In this paper, a continuous power flow that to somehow solve the singularity of Jacobian matrix of load distribution and divergence of the conventional power flow calculations in the vicinity of collapse point, is used for proper placement of UPFC to compensate for reactive power losses and to improve stability margin of static voltage.

\section{STATIC VOLTAGE STABILITY AND SYSTEM LOADING LIMIT}

In a power system with a certain topology structure and reactive power sources, if we increase the electrical load of its sheens, we will naturally face voltage drop that can be compensated by injecting reactive power. If, after injecting all the available reactive power sources, still we try to increase the consuming load, we will reach to a point in which every increase in load leads to voltage instability. The 
corresponding load to this point is generally called system loading limit in regard to static voltage stability. Since in this process it is assumed that the stability limit is obtained with regard to very gradual changes, the equations that govern system behavior are essentially comprised of load distribution equations. The maximum loading point (MLP), which is its static stability limit, is corresponding to the Bifurcation point of system and it means any increase in active or reactive load of system will lead to significant decrease and finally collapsing the voltage of sheens.

In other words, in this point, the solvability of the equations of load distribution that express the relationship and changes between load and voltage range is broken that mathematically means the singular jacobian matrix of load distribution equations. The tools usually used to display the dependence of voltage range of sheens to its consuming active or reactive load, are $\mathrm{P}-\mathrm{V}$ curve and $\mathrm{Q}-\mathrm{V}$ curve corresponding to that sheen.

\section{P-V Curve}

The P-V curve of sheen shows how the voltage of that sheen changes according to the increase of active or reactive power of that sheen or the entire network. This curve is used to identify the MW distance of current functional point to collapse point. A P-V curve is shown in Figure 1. In this curve, "P" is the load active power, as a parameter that gradually change and $\mathrm{V}$ is the sheen voltage of the load. According to figure, there are three area related to "P" parameter. In the first area, power distribution has two different solutions for each "P", stable voltage and unstable voltage. When "P" increases, system enter second area, where the two solutions overlap and constitute only a single point. This point represents the exploitation conditions and system operating point. Any load increase over this leads to insolvable equations and consequently static collapse of system [6].

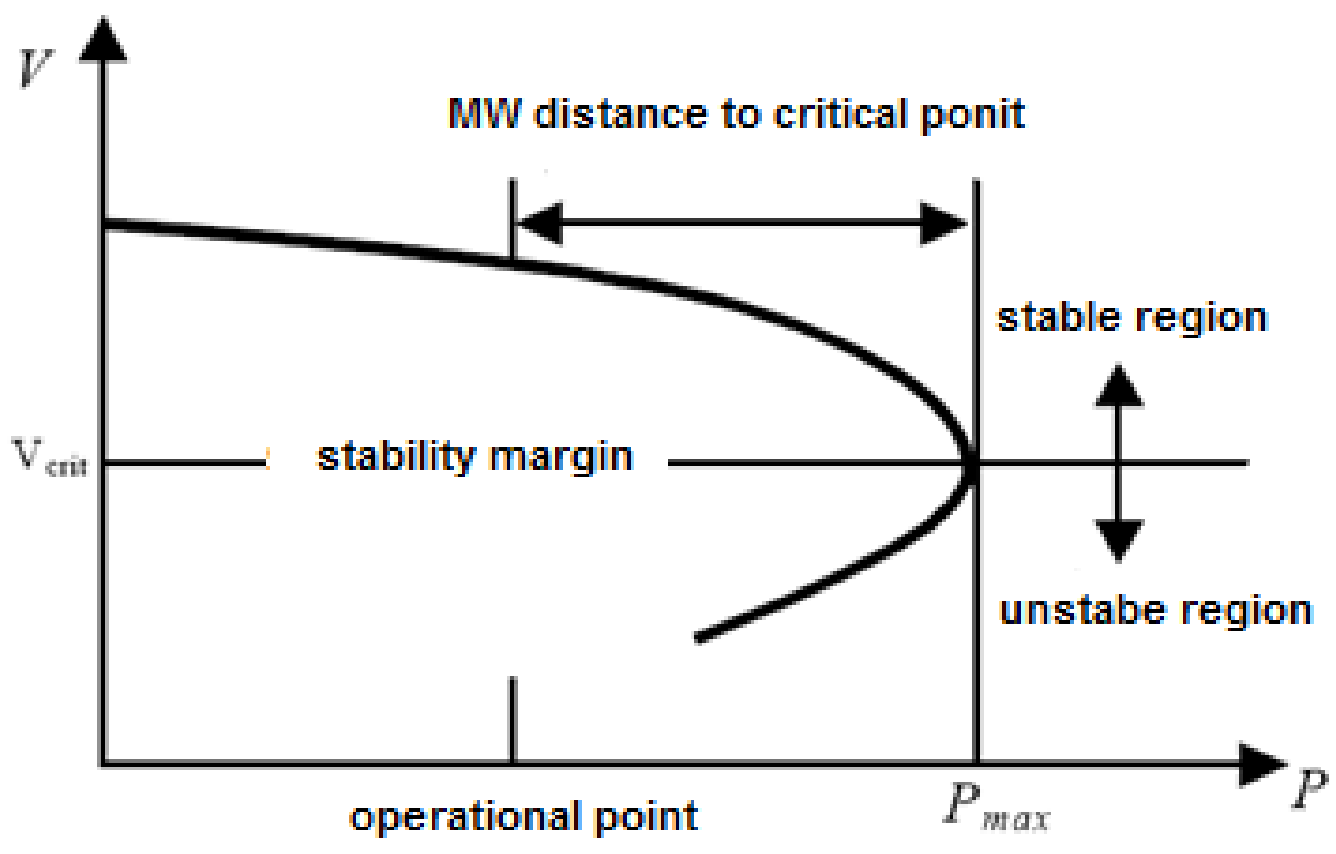

Figure 1. P-V curve

\section{Q-V Curve}

These curves are created, as p-v curves, through a set of power distribution simulation. These curves depict the voltage in a critical sheen depending on the reactive power in the same critical sheen. These curves are used to determine the proximity to voltage collapse.
Using these curves allow the designer to know the amount of maximum accessible reactive power after adding to weakest sheens and before reaching to minimum voltage or voltage instability. A Q-v curve is shown in Figure 2. Q axe shows the reactive power that should be added to or subtracted from the sheen to maintain the voltage in a specific load. 


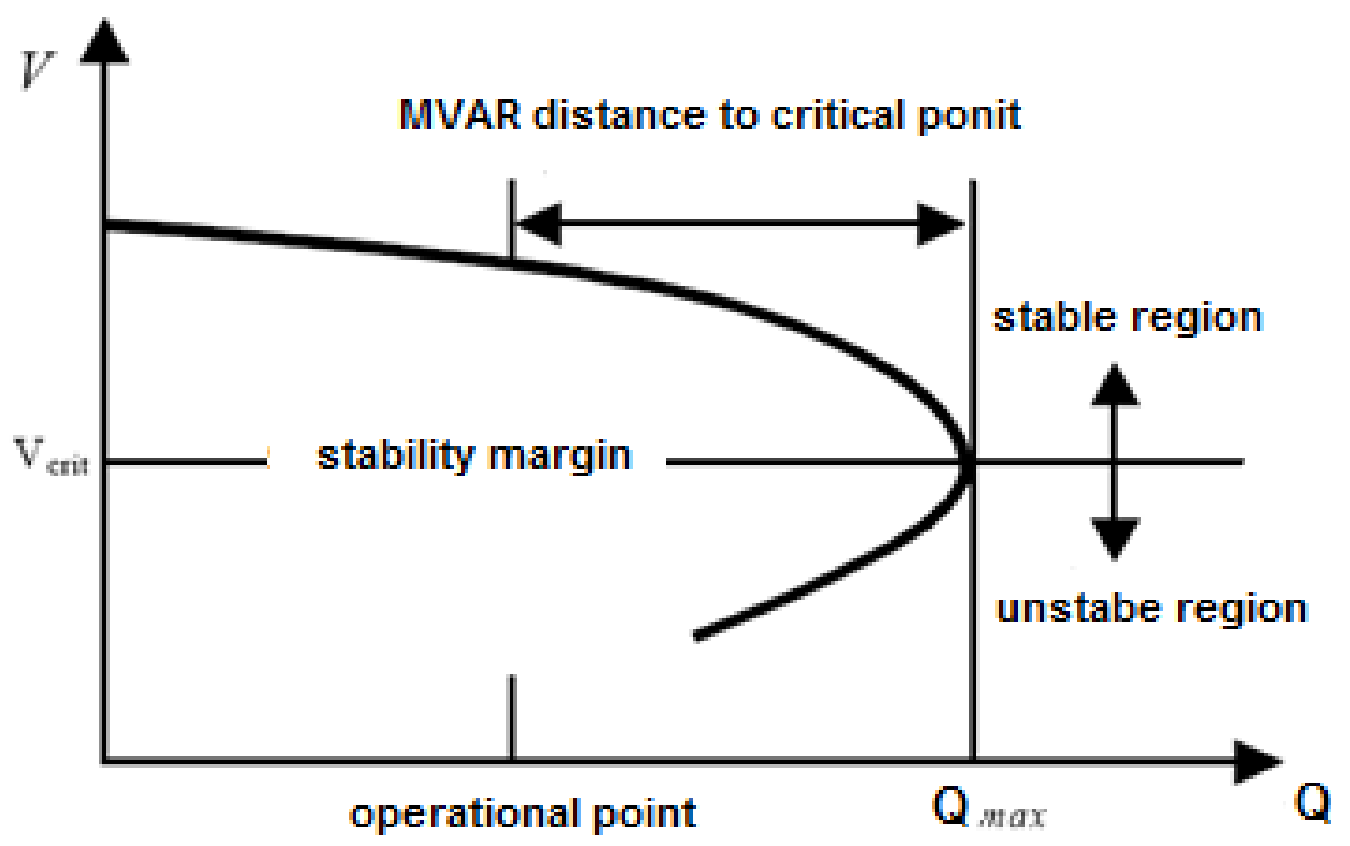

Figure 2. Q-V curve

Reactive power margin is the Mvar distance of operational point to collapse point [6]. However this method encounters some problems. One of the most important problems among them is selecting proper bus to draw the curve.

\section{EFFECT OF FACTS DEVICES ON THE VOLTAGE STABILITY}

As we know, the current power systems are very extensive and interconnected. Probably the most complex man-made device is power system. One of the main components of these systems is transmission lines. These lines are used to transfer electrical energy from the power station to the consumption centers. Obviously, the transmission line must be highly reliable and efficient. On the other hand energy consumption increasingly grow and there is a greater need for power transmission thus new transmission lines should be constructed or the existing lines should be equipped to provide more uses with least cost. Moreover, in some cases, due to natural and environmental problems and huge costs, construction of new transmission lines is difficult and sometimes impossible and we have to take maximum advantage of the existing lines. It caused power system operate close to the voltage stability limit. So, it is difficult to control the reactive power demand for such a system. Consequently the voltage stability of system will be affected, In such a way that will lead to voltage collapse.

The studies of voltage collapse are conducted with the aim of maximizing loading capacity in a specific transmission line. Typically, parallel and series compensation are used in order to maximize the capacity of the transmission line [7]. In 1998, Electric Power Research Association (EPRI) in the United States, have presented a new approach under the name of flexible alternating current transmission systems (FACTS) to compensate and maximize the capacity of transmission lines. Such devices are tools that in addition to increasing system load cause the power system to be under controlled and improve system stability by their high velocity [7].

Institute Of Electrical and Electronics Engineers (IEEE), define FACTS tools as follow [8]:

Using power electronics-based controllers in flexible transmission systems to increase the power transfer capability and improve system controllability. Increase the power transfer capability is done by controlling three basic parameters; Voltage, impedance and the angle of high voltage AC transmission line. Using FACTS devices in electric power transmission system has several advantages. The following is a brief overview of some of them. 
KAMARPOSHTI M. A., et al.
A) the efficient use of existing transmission facilities
B) Increase the reliability and availability of the transmission system
C) Increase transient and dynamic stability of networks and reduce looped circulation
D) Enhance power quality for sensitive industries
E) Environmental benefits
F) Financial Benefits of FACTS devices

\section{The use of FACTS devices with continuation power flow}

Usually, an appropriate supporting location for reactive power in the "weakest bus" enhances voltage stability margins. Weakest bus is defined as the nearest bus to the point of a voltage collapse [9]. Observed from the P-V curve, it is clear that the weakest bus is the ratio of the voltage differential changes to the differential change of big load. Changes of bus voltage for a given change in the system load are utilizable from tangent vectors that can be easily obtained from the Predicting steps in the process of continuous load distribution. With the reformulation of load equations, differential change in the reactive power is as follows:

$$
d P_{\text {total }}=C d \lambda
$$

Then the weakest would be:

$$
B U S=\max \left\{\left|\frac{d V_{1}}{C d \lambda}\right|,\left|\frac{d V_{2}}{C d \lambda}\right|, \ldots,\left|\frac{d V_{n}}{C d \lambda}\right|\right\}
$$

Thus, the value of $C d \lambda$ for each $d V$ element in specified tangent vector is the same. Choosing the weakest bus is easily possible by choosing a bus with the greatest element of dv. Furthermore, in the above method, the weakest bus can be obtained through straight eigenvectors related to the smallest eigenvalue[10]. In the continuous load distribution method [11], by drawing the chart of voltage $(\mathrm{V})$ depending on loading $(\lambda)$ in the sheen, $\mathrm{V}-\lambda$ curve is obtained. The $\mathrm{V}-\lambda$ curve ridge is proportional to the maximum loading that can be displayed before system reach to the voltage collapse. System megawatt margin is, in fact, the megawatt calculated distance of base functional point to the $\mathrm{V}-\lambda$ curve ridge with or without applying probable event to system. Maximum megawatt margin for system is calculated as follow:

$$
M W M M=P_{\max }-P_{b a s e}
$$

Where, $P_{\text {base }}$ and $P_{\max }$ are consuming power in basic state and maximum state, respectively. By continuous load distribution method it is possible to appropriately identify the location of the weakest bus. By locating FACTS devices in the weakest bus to support reactive power, Static voltage stability margin can be effectively enhanced. By entering FACTS Devices in power system, equations and variables state of FACTS devices are entered in load distribution equations and the correction step in the process of continuous load distribution. The solution of the equations of new load distribution is similar to the equations of the common load distribution.
But each FACTS device has its own equations and state variables. The number of state variables is equal to the number of required FACTS equations in formulating of load distribution.

The process of voltage stability with FACTS by using continuous load distribution is shown in figure 3. It can be observed from Figure 3 that the equations of FACTS devices are added to the load distribution equations. New load distribution equations are added in the correct step in the process of CPF. 


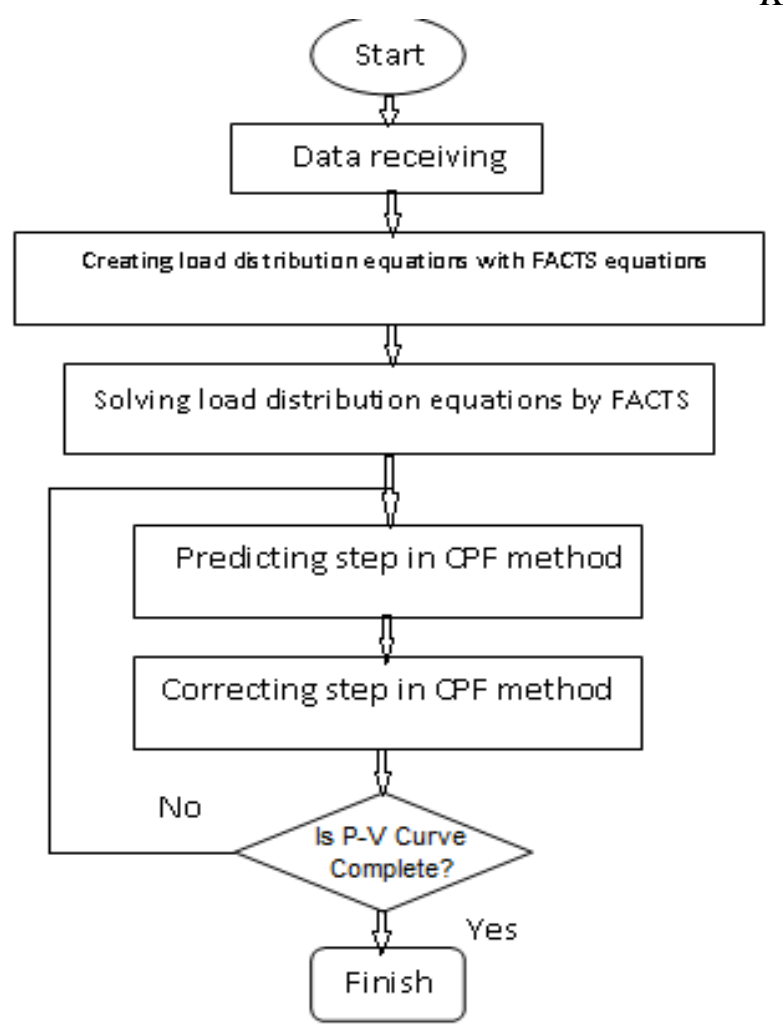

Figure 3. CPF process flowchart with FACTS

\section{Modeling of FACTS controllers}

Now different types of FACTS devices are used in power systems that in following lines their modeling in power system is described, these are as follow:

- Static Var compensator (SVC)

- Static synchronous compensator (STATCOM)
- Thyristor Controlled Series Compensation (TCSC)

- Static Synchronous Series Compensator (SSSC)

- Unified power function controller (UPFC)

Following general model for FACTS devices is used in voltage collapse studies. Algebraic and differential equations are as follows [1]:

$$
\begin{aligned}
x^{\bullet} & =f_{c}\left(x_{c}, V, \theta, u\right) \\
P & =g_{p}\left(x_{c}, V, \theta\right) \\
Q & =g_{p}\left(x_{c}, V, \theta\right)
\end{aligned}
$$

Where, $x_{c}$ is the system control variable, $u \in R^{n}$ algebraic variables corresponding to the models of the constant state elements, $f_{c}$ is a vector function of differential equations, $g_{p}$ indicates equations expression and algebraic variables $\mathrm{V}$ and $\theta$ identify voltage range and phase in the buses to which FACTS devices are attached.

\subsection{UPFC (unified power function controller)} UPFC arises from the connection of SSSC and STATCOM devices that consist of two VSI convertors; one of them is parallel attached to the network through parallel transformer and the other in series through a series transformer. Series and parallel parts of UPFC are fed together with a DC capacitor. In regard to capability, UPFC perform all series and parallel compensation together and can continuously control the phase angle, impedance, and voltage range. Thus, it can independently control the real power and reactive power of the transmission line. 
Figure 4 shows the equivalent circuit of UPFC.

equations are described as follows:

According to Figure $\mathbf{4}$ load distribution

$$
\begin{gathered}
P_{k}=P_{s h}+\sum\left\{\bar{V}_{k} \bar{I}_{m}^{*}\right\} \\
Q_{k}=Q_{s h}+\sum\left\{\bar{V}_{k} I_{m}^{*}\right\} \\
P_{m}=-\sum\left\{\bar{V}_{m} \bar{I}_{m}^{*}\right\} \\
Q_{k}=-\sum\left\{\bar{V}_{m} \bar{I}_{m}^{*}\right\}
\end{gathered}
$$

That $K_{s h}=\sqrt{\frac{3}{8} m s h}$

$P_{s h}$ and $Q_{s h}$ which are absorbed by parallel element, are as follow:

$$
\begin{aligned}
P_{s h}= & V_{k}^{2} G_{s h}-K_{s h} V_{d c} V_{k} G_{s h} \cos \left(\theta_{k}-\alpha\right) \\
& -K_{s h} V_{d c} V_{k} B_{s h} \sin \left(\theta_{k}-\alpha\right) \\
Q_{s h} & =V_{k}^{2} B_{s h}-K_{s h} V_{d c} V_{k} B_{s h} \cos \left(\theta_{k}-\alpha\right) \\
& -K_{s h} V_{d c} V_{k} G_{s h} \sin \left(\theta_{k}-\alpha\right)
\end{aligned}
$$

For DC circuit the following differential equation is used [1]:

$$
\begin{aligned}
V_{d c} & =\frac{P_{s h}}{C V_{d c}}+\frac{\sum\left\{\overline{V I}_{m}^{*}\right\}}{C V_{d c}} \\
& =\frac{V_{d c}}{R_{c} C}-\frac{R_{s h}\left(P_{s h}^{2}+Q_{s h}^{2}\right)}{C V_{d c} V_{k}^{2}}-\frac{R_{s e} I_{m}^{2}}{C V_{d c}}
\end{aligned}
$$

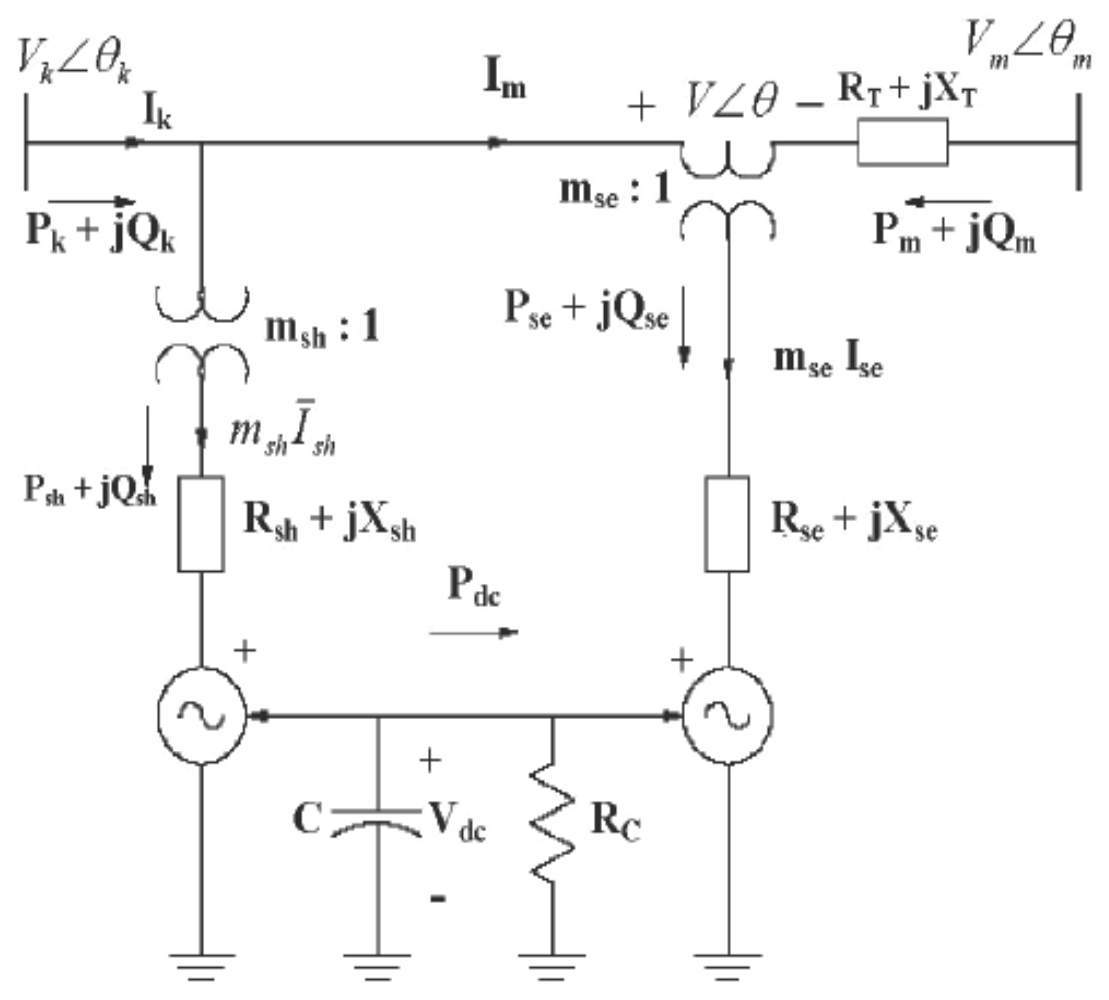

Figure 4. Equivalent circuit UPFC 


\section{SIMULATION RESULTS WITH} CONTINUATION POWER FLOW ON 14BUS IEEE

Our system is a 14-bus IEEE power system. Stimulated chart of 14-bus system in PSAT software [12] is drawn in Figure 5. This system has five manufacturing units; bus 1 is assumed as the major bus (base) and consists of 16 transmission lines, 11 transformers and 4 load bus. In this system, manufacturing units as standard PV buses, are modeled by the limit of $\mathrm{P}, \mathrm{Q}$ and loads are assumed as constant PQ loads.

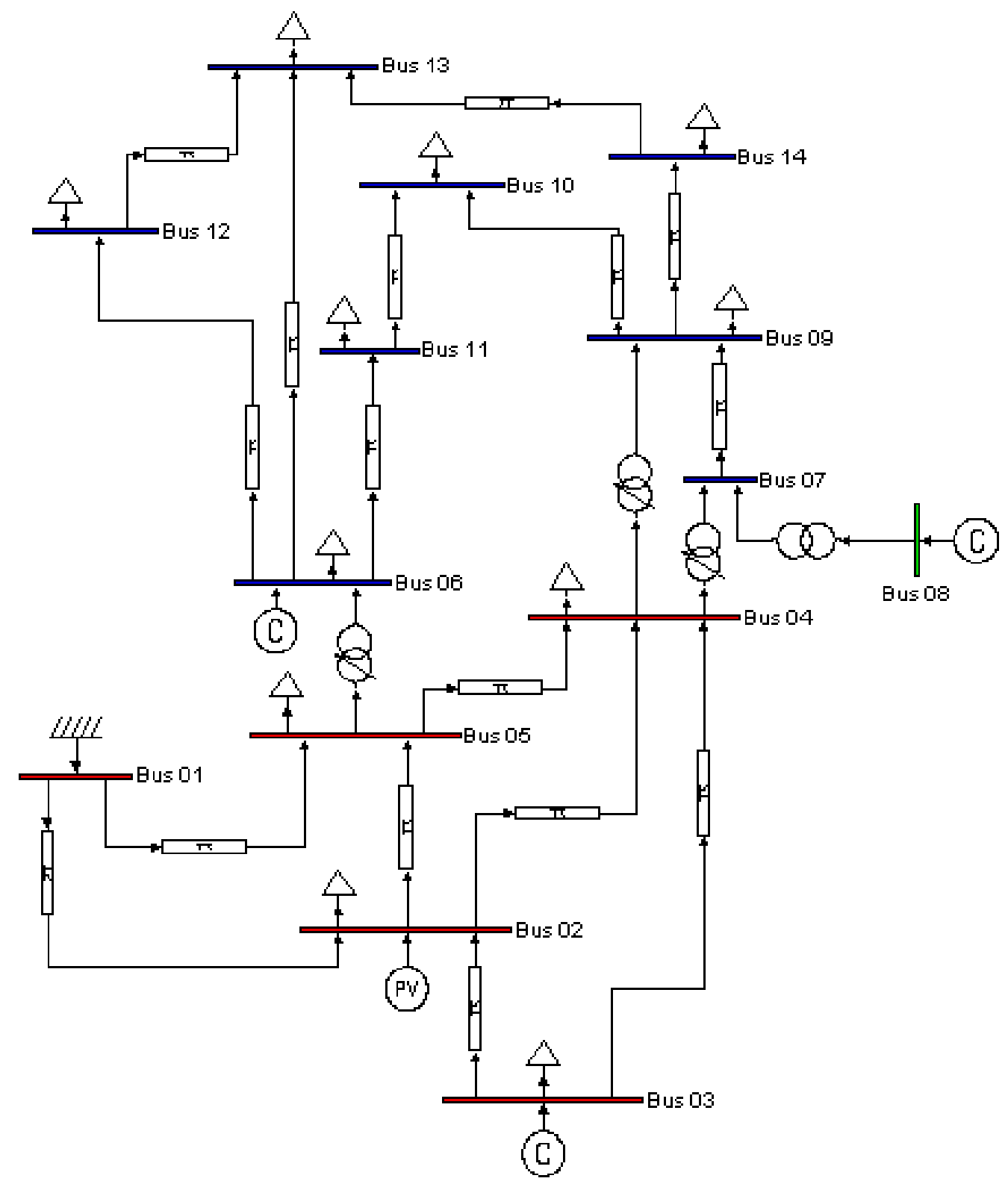

Figure 5. The chart of 14-bus system simulated by PSAT software

1. Simulation results without UPFC installation

By applying continuous load distribution on system, $V-\lambda$ curve is created and critical areas are identified. According to Figure 6, the maximum amount of loading point is calculated as 2.769 per unit. It is also sowed in this figure that, while under loading, 4,5,9 and 14 bus are more subjected to voltage instability. The voltage of all the buses under maximum loading condition is given in Figure 6. 


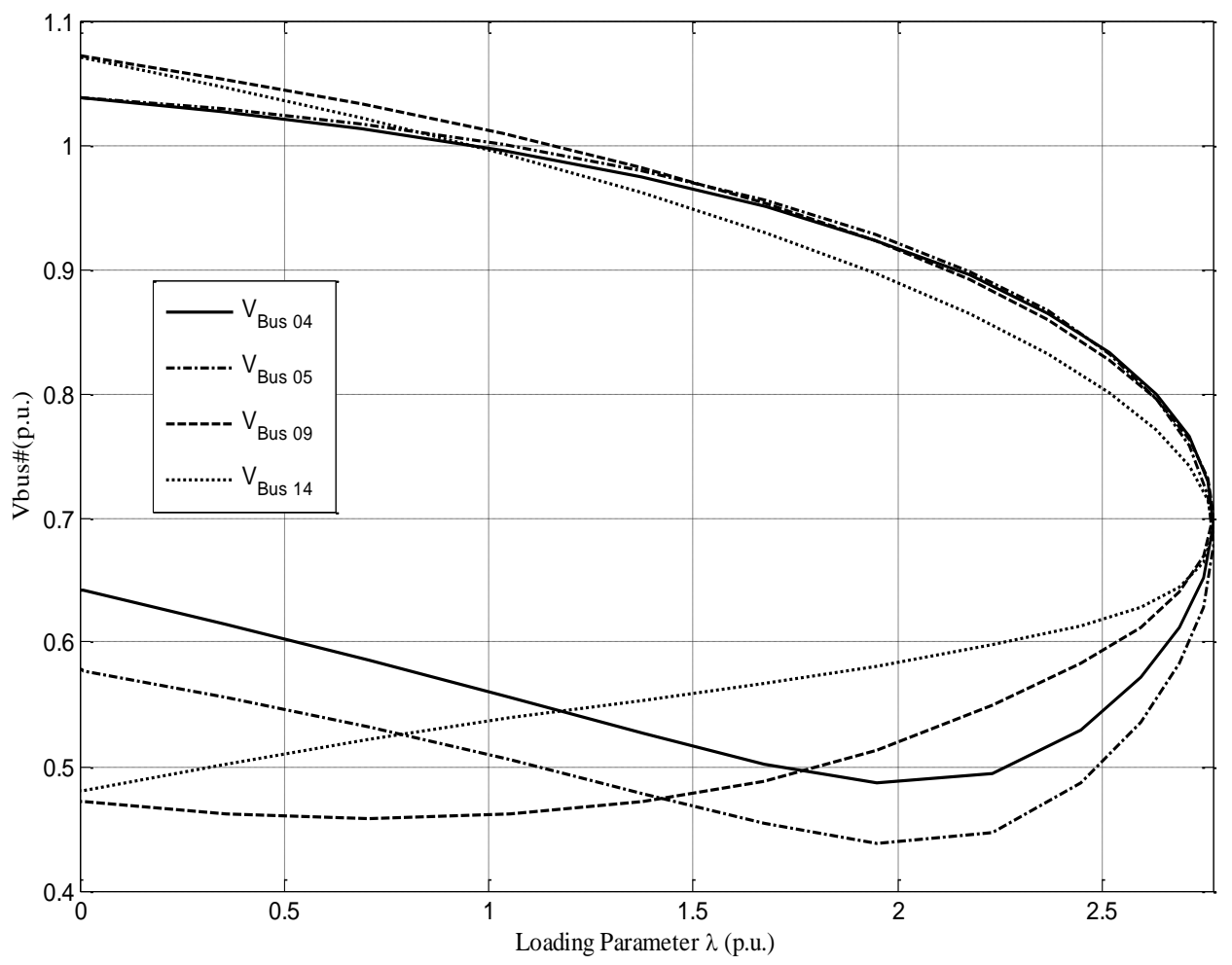

Figure 6. V- $\lambda$ curves of critical buses

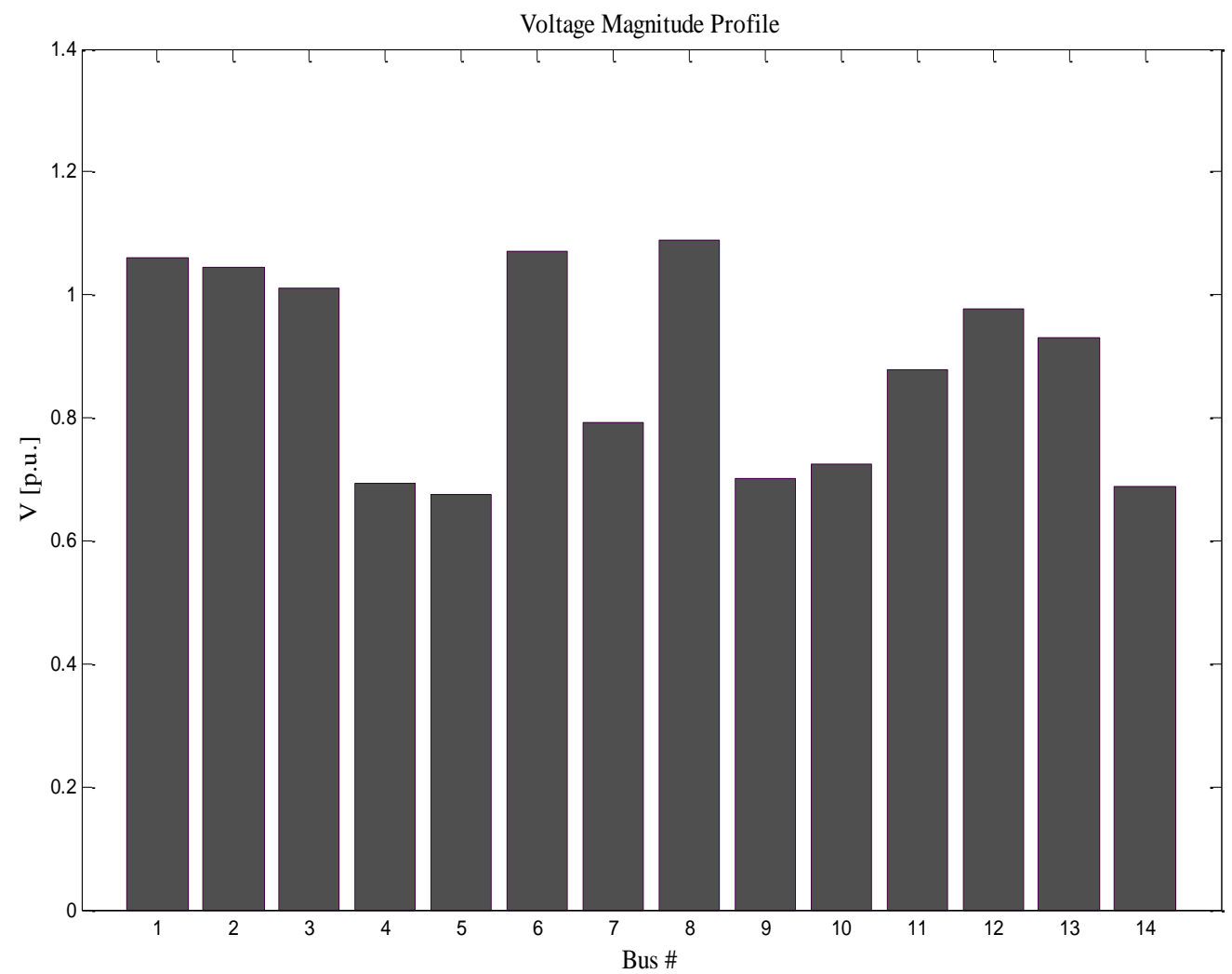

Figure 7. Voltage range profiles of all buses in the maximum loading point in the IEEE 14-bus system 
The voltage range profiles of all buses in the maximum loading point are also showed in Figure 7. According to figures (6) and (7), bus 5 with voltage 0.676 per unit, is the weakest bus in maximum loading of system, in which by increasing load demand, voltage rapidly drop and subject to more static instability.

\section{Simulation results with UPFC installation}

Rapid progress of power electric technology provides extraordinary facilities for better exploitation of available systems.

Table 1. The results of UPFC installation in the lines

\begin{tabular}{|c|c|c|c|}
\hline \multirow{2}{*}{$\begin{array}{c}\text { Maximum } \\
\text { loading } \\
\text { point } \\
\lambda_{\text {max }}\end{array}$} & \multicolumn{3}{|c|}{$\begin{array}{c}\text { The location of UPFC } \\
\text { installation }\end{array}$} \\
\cline { 2 - 4 } & \multicolumn{2}{|c|}{ Bus } & \multirow{2}{*}{ Line } \\
\cline { 2 - 4 } & to & from & \\
\hline 2.30874 & 5 & 2 & 1 \\
\hline 2.5735 & 12 & 6 & 2 \\
\hline 2.7828 & 13 & 12 & 3 \\
\hline 2.6049 & 13 & 6 & 4 \\
\hline 2.5853 & 11 & 6 & 5 \\
\hline 2.8429 & 10 & 11 & 6 \\
\hline 2.95 & 10 & 9 & 7 \\
\hline 2.9619 & 14 & 9 & 8 \\
\hline 2.85657 & 13 & 14 & 9 \\
\hline 2.9213 & 9 & 7 & 10 \\
\hline 2.8149 & 2 & 1 & 11 \\
\hline 2.7432 & 2 & 3 & 12 \\
\hline 2.6262 & 4 & 3 & 13 \\
\hline 2.9349 & 5 & 1 & 14 \\
\hline 3.1285 & 4 & 5 & 15 \\
\hline 2.5368 & 4 & 2 & 16 \\
\hline
\end{tabular}

Therefore, various controlling devices, under the name of flexible alterative current transfer systems (FACTS), are designed.

Table 2. The results of the calculation of megawatt margin with UPFC installation in lines

\begin{tabular}{|c|c|c|c|}
$\begin{array}{c}\text { The } \\
\text { location } \\
\text { of UPFC } \\
\text { installati } \\
\text { on }\end{array}$ & $\begin{array}{c}\text { Consuming } \\
\text { active } \\
\text { power in } \\
\text { basic load } \\
\text { (p.u.) }\end{array}$ & $\begin{array}{c}\text { Consuming } \\
\text { active } \\
\text { power } \\
\text { in } \lambda_{\max } \\
\text { (p.u.) }\end{array}$ & $\begin{array}{c}\text { Mega } \\
\text { watt } \\
\text { margi } \\
\text { n } \\
\text { (p.u.) }\end{array}$ \\
\hline 1 & 3.626 & 8.3715 & 4.7455 \\
\hline 2 & 3.626 & 9.3314 & 5.7054 \\
\hline 3 & 3.626 & 10.0905 & 6.4645 \\
\hline 4 & 3.626 & 9.4455 & 5.8195 \\
\hline 5 & 3.626 & 9.3742 & 5.7482 \\
\hline 6 & 3.626 & 10.3085 & 6.6825 \\
\hline 7 & 3.626 & 10.6969 & 7.0709 \\
\hline 8 & 3.626 & 10.7398 & 7.1138 \\
\hline 9 & 3.626 & 10.3579 & 6.7319 \\
\hline 10 & 3.626 & 10.5926 & 6.9666 \\
\hline 11 & 3.626 & 10.207 & 6.581 \\
\hline 12 & 3.626 & 9.9469 & 6.3209 \\
\hline 13 & 3.626 & 9.5225 & 5.8965 \\
\hline 14 & 3.626 & 10.6418 & 7.0158 \\
\hline 15 & 3.626 & 11.3438 & 7.7178 \\
\hline 16 & 3.626 & 8.5456 & 4.9196 \\
\hline & & & \\
\hline
\end{tabular}

FACTS can be effectively used to control power pass and improve static stability of voltage. The effect of UPFC in improving stability margin and increasing maximum loading point is examined according to modeling and UPFC described in subsection3-2-1. The results of installing UPFC in lines are presented in Table 1. It is observed that by installing UPFC in line 1 , connected to sheen 2 to 5 with $\lambda_{\max }=2.30874$ per unit, system has the lowest loading point and by installing it in line 15 , connected to sheen 5 to 4 with $\lambda_{\max }=3.1285$ per unit, system has the most loading point.

By installing UPFC in proper place it is possible to effectively support reactive power. The most proper place for installing UPFC is line 15 that show the most effect on increasing system loading margin and improving static voltage stability. According to equation 3, the megawatt 
margin of system is calculated by installing UPFC in the lines. These results are given in Table 2. It is observed that installing UPFC in line15, with increase in megawatt margin (7.7178 p.u.) has the most effect on the static loading limit, and its installation on line 1 has the lowest effect (4.7455 p.u.).

\section{CONCLUSION}

Using flexible alternative current transmission system can be the best option to adjust and control voltage instead of creating new transmission lines. Utilizing reactive power sources, which are parallel capacitors or flexible alternating current transmission systems controllers (FACTS), in proper place, can effectively improve loading level and the system voltage stability. By proper placement of FACTS devices which results in reactive power compensation, Static voltage stability margin can be effectively enhanced. The simulation results show that installing UPFC in line 15 causes more increase in voltage static loading margin of system.

\section{ACKNOWLEDGMENTS}

We would like to thank from Young Researchers and Elite Club, Jouybar Branch, Islamic Azad University, Jouybar, Iran.

\section{REFERENCES}

1. M. Ahmadi Kamarposhti, M. Alinezhad, H. Lesani, N. Talebi, "Comparison of SVC, STATCOM, TCSC, and UPFC Controllers for Static Voltage Stability Evaluated by Continuation Power Flow Method," The IEEE 8th Annual Electrical Power \& Energy Conference, Canada, October, pp. 1-8, 2008.

2. G. Morison, B.Gao and P. Kundur, "Voltage Stability Analysis Using Static and Dynamic Approaches," IEEE Trans. on Power Systems, Vol. 8, No. 3, pp. 1159-1171, Aug. 1993.
3. C. A. Cañizares, A. Z. de Souza, and V. H. Quintana, "Comparison of performance indices for detection of proximity to voltage collapse," IEEE Trans. Power Systems, vol. 11, no. 3, pp. 1441-1450, August 1996.

4. Y.L. Chen, "Weak Bus-Oriented optimal Multi-objective VAR Planning," IEEE Transactions on Power Systems, vol.11, no.4, pp.1885-1890, November 1996.

5. Thukaram, D. and Abraham Lomi, "Selection of Static VAR Compensator location and size for system voltage stability improvement", Journal of Electric Power System Research, Vol. 54, pp 139-150, 2000.

6. C. W. Taylor, "Power System Voltage Stability," New York: MaHraw-Hill, 1994.

7. R. Natesan and G. Radman, "Effects of STATCOM, SSSC and UPFC on Voltage Stability" Proceedings of the system theory thirty- Sixth southeastern symposium, pp. 546-550, 2004.

8. Cigre 95 TP108, FACTS Overview, IEEE Power Engineering Society, 1995.

9. A. Sode-Yome and N. Mithulananthan, "Comparison of shunt capacitor, SVC and STATCOM in static voltage stability margin enhancement," International Journal of Electrical Engineering Education, UMIST, Vol. 41, No. 3, July 2004.

10. M. Ahmadi Kamarposhti and M. Alinezhad, "Effects of FACTS Controllers on Maximum Loading Point to Study Static Voltage Collapse Phenomena" 23rd International Power System Conference, Tehran, PSC 2008.

11. V.Ajjarapu. C.Christy, The continuation power flow: A tool for steady state voltage stability analysis, IEEE Transactions on Power Systems, Vol.7, No.1, pp. 416-423, Feb.1992.

12.F. Milano, "Power System Analysis Toolbox," Version 2.1.2, Software and Documentation, 2008. 